\title{
Hubungan Kepuasan Kerja dengan Kinerja Perawat di Rumah Sakit
}

\author{
Raja Syafrizal $^{1 *}$, Yulihasri ${ }^{2}$, Zifriyanthi Minanda Putri ${ }^{3}$ \\ ${ }^{1}$ Pasca Sarjana, Fakultas Keperawatan Universitas Andalas, Padang \\ ${ }^{2}$ Fakultas Ekonomi, Universitas Andalas, Padang \\ ${ }^{3}$ Fakultas Keperawatan, Universitas Andalas, Padang \\ *Correspondence email: rajasyafrizal336@gmail.com
}

\begin{abstract}
Abstrak. Kinerja perawat dapat dilihat dari beberapa kasus yang terjadi di Rumah sakit. Kejadian jatuh pada pasien, infeksi nosokomial, pendokumentasian yang belum sesuai merupakan hasil kinerja perawat yang masih rendah. Faktor yang mempengaruhi kinerja perawat di rumah sakit yaitu kepuasan kerja. Sehingga penelitian ini bertujuan untuk menggambarkan hubungan kepuasan kerja dengan kinerja perawat. Penelitian ini menggunakan desain crossectional study dengan jumlah sampel 85 orang perawat pelaksana di RSUD Arosuka dengan teknik proportional sampling. Instrumen penelitian menggunakan kuesioner job satisfaction survey dan Individual Work Performance quastion (IWPQ) dan uji statistik yang digunakan uji distribusi frekuensi dan chi -square. Hasil penelitian didapatkan bahwa kepuasan kerja perawat mayoritas dalam kategori puas sebanyak 56.5\% dan kinerja perawat mayoritas kategori tinggi sebanyak 51.8\%. Kemudian didapatkan hubungan yang signifikan antara kepuasan kerja dengan kinerja perawat dengan p-value 0.000. Sehingga diharapkan rumah sakit dapat memperhatikan aspek kepuasan kerja perawat dalam membuat kebijakan.
\end{abstract}

Kata Kunci: Kepuasan Kerja; Kinerja

\begin{abstract}
The performance of nurses can be seen from several cases that occur in hospitals. The incidence of falls in patients, nosocomial infections, inadequate documentation is the result of nurses' low performance. Factors that affect the performance of nurses in hospitals are job satisfaction. So this study aims to describe the relationship between job satisfaction and nurse performance. This study used a cross-sectional study design with a sample of 85 nurses at Arosuka Hospital using proportional sampling technique. The research instrument used a job satisfaction survey questionnaire and the Individual Work Performance quasi (IWPQ) and statistical tests used frequency distribution and chi-square tests. The results showed that the majority of nurses' job satisfaction was in the satisfied category as much as $56.5 \%$ and the majority of nurses' performance in the high category was $51.8 \%$. Then obtained a significant relationship between job satisfaction and nurse performance with a p-value of 0.000 . So it is expected that hospitals can pay attention to aspects of nurse job satisfaction in making policies
\end{abstract}

Keywords: Job Satisfaction; Performance

\section{PENDAHULUAN}

Menurut Nursalam, (2016) menyatakan bahwa kinerja merupakan hasil kerja yang dicapai oleh seseorang atau sekelompok orang dalam suatu organisasi sesuai dengan wewenang dan tanggung jawab masingmasing untuk mencapai tujuan organisasi yang tidak melanggar hukum dan sesuai etika. Kinerja diartikan juga sebagai usaha dari hasil pekerjaan dalam menjalankan fungsi atau kegiatan selama periode tertentu. Gambaran kinerja perawat dirumah sakit diteliti oleh Loah \& Magari, (2015) menyatakan bahwa kinerja perawat baik sebesar $53.33 \%$ dan berkinerja kurang baik $46.67 \%$ dalam melaksanakan perawatan pada pasien kardiovaskuler.

Kinerja perawat di rawat inap pada rumah sakit umum daerah Batusangkar memiliki kinerja kurang baik sebesar 57.8\% (Handayani et al., 2018). Kinerja perawat juga diteliti oleh Mosse, (2020) menyatakan bahwa gambaran kinerja perawat kategori baik (33\%), kategori cukup $(43 \%)$ dan kinerja kategori kurang baik (24\%). Hal ini dapat memberikan gambaran yang jelas bahwa kinerja perawat di rumah sakit belum maksimal sehingga akan berdampak pada pelayanan di rumah sakit. Peningkatan kinerja dapat dipengaruhi oleh beberapa faktor. Faktor yang mempengaruhi kinerja terdiri dari variabel individu, variabel organisasi dan psikologi (Gibson, 1997 dalam Nursalam, (2016). Penelitian yang dilakukan oleh Thulth \& Sayej, (2015) menyatakan faktor yang mempengaruhi kinerja yaitu beban kerja sebesar $79.2 \%$, dukungan manajer sebesar $72 \%$ dan ketersediaan sumber daya sebesar $69.8 \%$. Bawono \& Nugraheni (2015) pemberian intensif dan kepemimpinan memiliki hubungan positif dan signifikan kinerja perawat.

Kinerja perawat juga dipengaruhi oleh motivasi, etos kerja, lingkungan kerja, kompetensi dan kepuasan kerja (Supriyadi, 2017). Beberapa penelitian tersebut memberikan gambaran bahwa pentingnya kepuasan kerja dalam bentuk pemberian intensif dan reward dalam meningkatkan kinerja perawat. Kepuasan kerja menjadi faktor psikologi terhadap kinerja. Menurut (Robbins, 2015) menyatakan seseorang yang memiliki kepuasan kerja yang tinggi akan memiliki perasaan positif begitu juga sebaliknya seseorang dengan kepuasan kerja rendah memiliki perasaan negatif terhadap pekerjaannya.

Platis et al., (2015) kepuasan kerja memiliki hubungan yang kuat dengan kinerja. Lingkungan kerja, kepemimpinan transformasional dan kepuasan kerja 
berpengaruh signifikat terhadap kinerja perawat (Saleh et al., 2016). Menurut Al-Banna, (2018) menyatakan bahwa ada korelasi positif yang kuat antara kepuasan kerja perawat dan prestasi kerja mereka di rumah sakit selama memberikan perawatan kesehatan. Tujuan dari penelitian ini adalah untuk mengetahui hubungan kepemimpinan transformasional dan kepuasan kerja terhadap kinerja perawat di rumah sakit umum daerah Arosuka.

\section{METODE}

Penelitian ini menggunakan desain crossectional study, dengan sampel penelitian perawat pelaksana yang berjumlah sebanyak 85 responden. Pengambilan sampel dengan teknik proportional sampling. Penelitian menggunakan instrumen job satisfaction survey dikembangkan oleh (Spector, 1994) dan Individual Work Performance quastion (IWPQ) yang dikembangkan oleh (Koopmans et al., 2014). Instrumen dilakukan uji reabilitas dengan hasil kuesioner prestasi kerja individual (IWPQ) yaitu cronbach alpha 0.953. Kuesioner job satisfaction survey memiliki nilai reabilitas yaitu cronbach alpha 0.975. Uji analisis statistik yang digunakan adalah uji distribusi frekuensi dan uji chisquare.

\section{HASIL DAN PEMBAHASAN \\ Distribusi Frekuensi Kepuasan Kerja}

Hasil distribusi frekuensi kepuasan kerja dapat terlihat pada tabel 1 sebagai berikut:

Tabel 1. Distribusi dan Frekuensi Kepuasan Kerja Perawat $(\mathrm{n}=85)$

\begin{tabular}{ccc}
\hline Kepuasan Kerja & Frekuensi (f) & Persentase (\%) \\
\hline Tidak Puas & 5 & 5.9 \\
Kurang Puas & 32 & 37.6 \\
Puas & 48 & 56.5 \\
Total & 85 & 100 \\
\hline
\end{tabular}

Berdasarkan data di tabel 1 didapatkan bahwa kepuasan kerja perawat mayoritas dalam kategori puas sebanyak $48(56.5 \%)$, sedangkan yang menyatakan kurang puas sebanyak $32(37.6 \%)$ dan tidak puas sebanyak $5(5.9 \%)$.

\section{Distribusi Frekuensi Kinerja Perawat}

Frekuensi kinerja perawat dapat terlihat pada tabel 2 sebagai berikut:

Tabel 2. Distribusi dan Frekuensi Kinerja Perawat ( $\mathrm{n}=85)$

\begin{tabular}{lcc}
\hline Kinerja & Frekuensi (f) & Persentase (\%) \\
\hline Rendah & 41 & 48.2 \\
Tinggi & 44 & 51.8 \\
Total & 85 & 100 \\
\hline
\end{tabular}

Berdasarkan data di tabel 2 didapatkan bahwa kinerja perawat di RSUD Arosuka dalam kategori tinggi sebanyak $44(51.8 \%)$, sedangkan kinerja rendah sebanyak $41(48.2 \%)$.

\section{Hubungan Kepuasan Kerja dengan Kinerja Perawat}

Hubungan kepuasan kerja dengan kinerja perawat dengan menggunakan uji statistik chi square yang dapat disajikan pada tabel 3 sebagai berikut:

Tabel 3. Hubungan Kepuasan Kerja dengan Kinerja Perawat

\begin{tabular}{|c|c|c|c|c|c|c|c|}
\hline & \multicolumn{6}{|c|}{$(n=85)$} & \multirow{3}{*}{$P$ value } \\
\hline \multirow[t]{3}{*}{ Kepuasan Kerja } & \multicolumn{4}{|c|}{ Kinerja } & \multicolumn{2}{|c|}{ Total } & \\
\hline & \multicolumn{2}{|c|}{ Rendah } & \multicolumn{2}{|c|}{ Tinggi } & & & \\
\hline & $f$ & $\%$ & $f$ & $\%$ & $\mathrm{n}$ & $\%$ & \\
\hline Tidak Puas & 4 & 80 & 1 & 20 & 5 & 100 & \\
\hline Kurang Puas & 25 & 78.1 & 7 & 21.9 & 32 & 100 & 0.000 \\
\hline Puas & 12 & 25 & 36 & 75 & 48 & 100 & \\
\hline Jumlah & 41 & 48.2 & 44 & 51.8 & 85 & 100 & \\
\hline
\end{tabular}

Berdasarkan data di tabel 3 menyatakan bahwa ada sebanyak 36 (75\%) perawat puas dalam pekerjaannya dan memiliki kinerja yang tinggi. Sedangkan sebanyak 7 (21.9\%) perawat kurang puas dalam pekerjaan dan memiliki kinerja yang tinggi dan sebanyak $1(20 \%)$ tidak puas dalam pekerjaannya memiliki kinerja yang tinggi. Hasil uji statistik diperoleh nilai $\mathrm{p}=0.000$ ( $\mathrm{P}$ value $<0.05)$ maka dapat disimpulkan terdapat hubungan yang signifikan antara kepuasan kerja dengan kinerja perawat.

\section{Pembahasan}

\section{Kepuasan Kerja Perawat di RSUD Arosuka}

Hasil penelitian mengatakan bahwa kepuasan kerja perawat di RSUD Arosuka mayoritas dalam kategori puas sebanyak 48 (56.5\%), sedangkan yang menyatakan kurang puas sebanyak 32 (37.6\%) dan tidak puas sebanyak 5 (5.9\%). Hasil ini didukung oleh penelitian Kousar et al., (2018) yang menyatakan bahwa sebagian besar perawat adalah puas dengan gaji mereka saat ini, tetapi mereka tidak puas dengan hadiah mereka bujukan dan struktur pelayanan perawat.Tingkat kepuasan kerja perawat, persentase tertinggi dari perawat yang menjawab cukup puas tentang umumkondisi kerja dan hubungan kerja, sedangkan persentase tertinggi dari peserta menjawab bahwa mereka tidak puas tentang gaji dan potensi promosi, penggunaan keterampilan dan kemampuan, dan aktivitas kerja (Al-Banna, 2018).

Kepuasan kerja diartikan juga sebagai bentuk perasaan positif tentang pekerjaan, yang dihasilkan dari suatu evaluasi dari karakteristik - karakteristiknyan (Robbins, 2015). Ketidakpuasan pekerjaan sering disebut sebagai alasan utama tingginya tingkat ketidakhadiran dan pergantian perawat yang menimbulkan ancaman bagi perawatan kesehatan sehingga hal ini menghambat efisiensi dan efektivitas mereka (Semachew et al., 2017). Studi lain mengatakan bahwa karyawan bahagia memiliki efek positif pada produktivitas, sehingga menyarankan bahwa kepuasan atau kebahagiaan dengan pekerjaan seseorang memiliki efek positif pada kinerja seseorang (Nono, 2017). 


\section{Kinerja Perawat di RSUD Arosuka}

Hasil penelitian ini mengatakan bahwa kinerja perawat di RSUD Arosuka dalam kategori tinggi sebanyak 44 (51.8\%), sedangkan kinerja rendah sebanyak 41 (48.2\%). Hal ini didukung oleh penelitian yang mengatakan bahwa kinerja perawat secara keseluruhan berada pada tingkat di atas rata-rata di unit neonatal dan di bawah rata-rata di departemen lain dan terdapat hubungan positif yang signifikan antara kinerja dan tingkat di unit perawatan intensif (Mokhtar, 2017). Yosiana et al., (2020) mengatakan bahwa rerata skor kinerja perawat adalah 4,04 dan termasuk dalam kategori tinggi hal ini bearti perawat di puskesmas telah mampu mengelola stres kerja mereka dengan baik.

Kinerja merupakan hasil kerja secara kualitas dan kuantitas yang dicapai oleh seorang pegawai dalam melaksanakan tugasnya sesuai dengan tanggung jawab yang diberikan kepadanya (Supriyadi, 2017). Faktor yang mempengaruhi kinerja yaitu jenis kelamin wanita, kepuasan kerja, lingkungan kerja dan diskriminasi pekerjaan (Ramlan et al., 2016). Faktor yang memiliki pengaruh prediktif signifikan terhadap kinerja perawat tingkat pelayanan kesehatan sekunder adalah stres, shift dan departemen kerja (Al-Makhaita et al., 2014). Stres dan kelelahan terkait pekerjaan berdampak negatif pada kinerja di rumah sakit umum (KFH) dan universitas (KAUH) tetapi tidak di rumah sakit swasta (IMC) (Qattan, 2017).

\section{Hubungan Gaya Kepuasan Kerja dengan Kinerja Perawat}

Hasil uji statistik diperoleh nilai $\mathrm{p}=0.000$ ( $\mathrm{P}$ value $<0.05)$ maka dapat disimpulkan terdapat hubungan yang signifikan antara kepuasan kerja dengan kinerja perawat. Hal ini sejalan dengan penelitian yang dilakukan oleh (Al-Banna, 2018) mengatakan bahwa ada korelasi positif yang kuat antara kepuasan kerja perawat dan kinerja mereka di rumah sakit selama memberikan perawatan kesehatan. Temuan penelitian lainnya mengungkapkan bahwa ada hubungan linier antara kepuasan kerja ( $\mathrm{Job}$ reward/Pay, Promotion, job safety/ keamanan dan kondisi kerja) dan proksi kinerja pegawai yaitu moral pegawai (Ezeanyim \& Ufoaroh, 2019). Kinerja perawat selalu bergantung pada tingkat kepuasan kerjanya (Kousar et al., 2018a). Robbins, (2015) menyatakan bahwa karyawan yang puas akan berbicara positif tentang organisasi, saling membantu yang pada akhirnya akan meningkatkan kinerja.

Kepuasan kerja dapat meningkatkan kinerja seorang pegawai dengan korelasi positif yang artinya jika kepuasan kerja seseorang tinggi maka kinerja nya akan tinggi, dan sebaliknya jika seorang pegawai tidak puas akan menampil kinerja yang buruk (Triwahyuni \& Ekowati, 2019). Kinerja yang baik menyiratkan peningkatan efisiensi, efektivitas, atau kualitas yang lebih tinggi dari penyelesaian serangkaian tugas yang diberikan kepada seorang karyawan dalam suatu organisasi atau perusahaan (Murty and Hudiwinarsih, 2016 dalam (Egenius et al., 2020). Sharma et al (2016) percaya bahwa kepuasan karyawan adalah diakui sebagai salah satu pendorong terpenting kualitas layanan, produktivitas, dan loyalitas karyawan.

\section{SIMPULAN}

Bedasarkan hasil penelitian dapat ditarik kesimpulan bahwa kepuasan kerja perawat mayoritas dalam kategori puas sebanyak $56.5 \%$ dan kinerja perawat mayoritas kategori tinggi sebanyak 51.8\%. Kemudian terdapat hubungan yang signifikan antara kepuasan kerja dengan kinerja perawat.

\section{DAFTAR PUSTAKA}

Al-Banna, D. (2018). Impact of nurse's satisfaction on work performance. Erbil Journal of Nursing \& Midwifery, $\quad$ l(1), 2-9. https://doi.org/10.15218/ejnm.2018.01

Al-Makhaita, H., Sabra, A., \& Hafez, A. (2014). Job performance among nurses working in two different health care levels, Eastern Saudi Arabia: a comparative study. International Journal of Medical Science and Public Health, 3(7), 832. https://doi.org/10.5455/ijmsph.2014.240420142

Bawono, D. C., \& Nugraheni, R. (2015). Analisis Pengaruh Pemberian Insentif, Kepemimpian Dan Beban Kerja Terhadap Kinerja Perawat. Diponegoro Journal of Management, 4, 1-14. http://ejournal-s1.undip.ac.id/index.php/dbr

Egenius, S., Triatmanto, B., \& Natsir, M. (2020). The effect of job satisfaction on employee performance through loyalty at credit union (CU) corporation of east kutai district, East Kalimantan. International Journal of Multicultural and Multireligious Understanding, 7(10), 480. https://doi.org/10.18415/ijmmu.v7i10.1891

Ezeanyim, E. E., \& Ufoaroh, E. T. \& A. (2019). The impact of job satisfaction on employee performance in selected public enterprise in Awka, Anambra State. Journal of Management and Business Research: A Administration and Management, 19(7), 11.

Handayani, S., Fannya, P., \& Nazofah, P. (2018). Faktor yang Berhubungan dengan Kinerja Tenaga Kesehatan Di Rawat INAP RSUD Batusangkar. Jurnal Endurance, 3(3), 440. https://doi.org/10.22216/jen.v3i3.3005

Koopmans, L., Bernaards, C. M., Hildebrandt, V. H., De Vet, H. C. W., \& Van Der Beek, A. J. (2014). Construct validity of the individual work performance questionnaire. Journal of Occupational and Environmental Medicine, 56(3), 331-337.

https://doi.org/10.1097/JOM.0000000000000113

Kousar, S., Hussain, M., Afzal, M., Gilani, P. A., \& Azhar, M. (2018a). Impact of job satisfaction on 
nurses $\hat{a} €^{\mathrm{TM}}$ performance. Saudi Journal of Nursing and Health Care, 1(1), 49-55. https://www.saudijournals.com/journaldetails/sjnhc/90/777

Kousar, S., Hussain, M., Afzal, M., Gilani, P. A., \& Azhar, M. (2018b). Impact of Job Satisfaction on Nurses $\mathfrak{a}^{\mathrm{TM}}$ Performance. Saudi Journal of Nursing and Health Care, 1(1), 49-55.

Loah, J. M., \& Magari, L. (2015). Perawatan pada Pasien Kardiovaskuler Di Cardio Vaskuler and Brain Center ( Cvbc ). JUPERDO, 4, 7-12.

Mokhtar, K. M. (2017). Job Performance among Nurses in Pediatric Department (Khartoum State 2015). Nursing \& Healthcare International Journal, 1(4). https://doi.org/10.23880/nhij-16000119

Mosse, M. M. (2020). Factors That Influence Nurses $\hat{\mathrm{a}} €^{\mathrm{TM}}$ Performance in Inpatients at the General Hospital. Journal for Quality in Public Health, 3(2), 642-651. https://doi.org/10.30994/jqph.v3i2.115

Nono, A.-G. (2017). The Determinants of Job Satisfaction among Nurses, Midwives, and Auxiliary Nurses in Health Clinics: The Case of Bénin, West Africa. The Determinants of Job Satisfaction among Nurses, Midwives, and Auxiliary Nurses in Health Clinics: The Case of Bénin, West Africa, May. https://doi.org/10.7249/rgsd373

Nursalam. (2016). Manajemen Keperawatan. Salemba Medika.

Platis, C., Reklitis, P., \& Zimeras, S. (2015). Relation between job satisfaction and job performance in healthcare services. Procedia - Social and Behavioral Sciences, 175, 480-487. https://doi.org/10.1016/j.sbspro.2015.01.1226

Qattan, A. (2017). The Effect of Work-Related Stress and Burnout on Nursing Performance and Job Satisfaction: a Study of Hospitals in Saudi Arabia. (Issue September) [the university of sheffield]. http://etheses.whiterose.ac.uk/20208/

Ramlan, M., Arshad, M., Tumpang, N. A., \& Osman, N. I. (2016). Job performance among nurses at Mawar Renal Medical Centre. Journal of Administrative Science, 13(1), 1-10.

Robbins, S. (2015). Perilaku Organisasi. Salemba Medika.

Saleh, A., Ramly, M., \& Gani, M. U. (2016). Factors affecting the job satisfaction and performance of nurses Private Hospitals Class B In Makassar. Factors Affecting The Job Satisfaction And Performance Of Nurses Private Hospitals Class B In Makassar, 5(10), 74-77.

Semachew, A., Belachew, T., Tesfaye, T., \& Adinew, Y. M. (2017). Predictors of job satisfaction among nurses working in Ethiopian public hospitals, 2014: Institution-based cross-sectional study. Human Resources for Health, 15(1), 1-8. https://doi.org/10.1186/s12960-017-0204-5

Spector, P. E. (1994). Job Satisfaction Survey. Department of Psychology University of South Florida.

Supriyadi. (2017). Faktor-Faktor yang Berhubungan dengan Kinerja Perawat di Rumah Sakit Islam PDHI Yogyakarta. Health Sciences and Pharmacy Journal, l(1),

30. https://doi.org/10.32504/hspj.v1i1.4

Thulth, A. S., \& Sayej, S. (2015). Selected organizational factors affecting performance of professional nurses in North West Bank Governmental Hospitals. Journal of Education and Practice, 6(7), 100-110.

Triwahyuni, R., \& Ekowati, V. (2019). The effect of work satisfaction on employee engagement. Polish Journal of Management Studies, 19(2), 101-111. https://doi.org/10.17512/pjms.2019.19.2.08

Yosiana, Y., Hermawati, A., \& Mas'ud, M. H. (2020). The Analysis of Workload and Work Environment on Nurse Performance with Job Stress as Mediation Variable. Journal of Socioeconomics and Development, 3(1), 37. https://doi.org/10.31328/jsed.v3i1.1326 